\title{
Nanogram per Deciliter
}

National Cancer Institute

\section{Source}

National Cancer Institute. Nanogram per Deciliter. NCI Thesaurus. Code C67326.

A unit of mass concentration defined as the concentration of one nanogram of a substance per unit volume of the mixture equal to one deciliter. The concept also refers to the unit of mass density (volumic mass) defined as the density of substance which mass equal to one nanogram occupies the volume of one deciliter. 